SHORT COMMUNICATION

\title{
Leucocoprinus birnbaumii (Agaricales: Basidiomycota), attractive yellow houseplant mushroom, revisited after 100 years
}

\author{
N.K.B. Adikaram ${ }^{1, *}$ D.M.D. Yakandawala ${ }^{2}$ and L. Jayasinghe ${ }^{1}$
}

${ }^{1}$ National Institute of Fundamental Studies (NIFS), Hantana Road, Kandy 20000, Sri Lanka. ${ }^{2}$ Department of Botany, University of Peradeniya, Peradeniya 20400, Sri Lanka.

Received: 15/09/2019 ; Accepted: 03/04/2020

\begin{abstract}
Sulphur yellow color fruiting bodies of a mushroom at several stages of development were found growing indoors, on decaying mosses (peat) inside a glass box in the University premises at Peradeniya in November 2018. The fungus was examined and identified by its morphological features, described previously, as Leucocoprinus birnbaumii. The present paper reports L. birnbaumii 110 years after its first record in Ceylon and describes its morphology using growth stages and color images for easy recognition.
\end{abstract}

Keywords: Houseplant mushroom, Agaricaceae.

\section{INTRODUCTION}

The "yellow houseplant mushroom" was first described in 1785 and named as Agaricus luteus (Bolton, 1788) invalidly as that epithet is already used. Corda (1839) described the same species, based on specimens as Agaricus birnbaumii. The species was transferred to the genus Leucocoprinus establishing its scientific name as Leucocoprinus birnbaumii in 1961 (Singer, 1962). This attractive fungus is commonly known as yellow houseplant mushroom, yellow parasol, flower-pot parasol or plant-pot dapperling.

The earliest record of the fungus in Sri Lanka (then Ceylon) was in 1844 (Gardener 47, illustrations only), the specimens were collected on the ground in Peradeniya (Kandy District, Central Province), followed by Thwaites in November 1867 and 1869 amongst decayed herbs, also from Peradeniya. Berkeley (1847:481, Berkeley \& Broome (1871:499), and Petch (1910:383) referred this mushroom species to Agaricus cepaestipes. The mushroom is said to be common in the tropics and subtropics and frequently occurs in flowerpots but last recorded in 1910 in Sri Lanka (Petch, 1910). This is the first record of the fungus in Sri Lanka after 1910 and also as L. birnbaumii, the currently accepted valid name. It can make a beautiful addition to the household flora.

Leucocoprinus birnbaumii was described, using morphological characteristics and line drawings, by Pegler in his book, Agaric Flora of Sri Lanka (1986) that illustrates early records of agarics in Ceylon mostly by Berkeley \& Broome (1870, 1871 and 1873). There are no photographic illustrations of fruit bodies of this common and interesting species of L. birnbaumii in Sri Lanka. The present paper reports the occurrence of $L$. birnbaumii 110 years after its first record in Ceylon and describes the morphology of this attractive garden mushroom of Sri Lanka using various growth stages and color images for its easy recognition.

\section{MATERIALS AND METHODS}

The study material was found growing indoors on decaying mosses (peat) placed in a medium-sized $\left(18 \times 24 \times 18\right.$ inch $\left.^{3}\right)$, square, glass tank at the Department of Botany, University of Peradeniya, Peradeniya (Kandy District, Central Province of Sri Lanka) in November 2018. Ecological features of the habitat were noted. Fruit bodies were photographed in situ and delivered to the laboratory at the National Institute of Fundamental Institute (NIFS), Kandy for visual and microscopic examination. Morphological characteristics were examined in fruit bodies of different stages of development and recorded. Measurements of the pileus and the stipe were taken. A spore print was obtained by placing a detached, mature pileus inverted on a black paper, for several hours. Basidiospores were mounted in a drop of lactophenol on a glass slide and examined under microscope (Euromax Stereo Zoom Microscope Model NZ.1903-P with Digital Camera CMEX 5) and photographed, the dimensions of 30 basidiospores were measured. The mean length and width were calculated and given with the range of spore measurements with extreme values in parentheses. Morphological features of the vegetative mycelium and reproductive structures were observed and recorded. The specimen was identified using the morphological descriptions given in Pegler (1986). The specimen was deposited in the fungal collection at the Department of Botany, University of Peradeniya (Accession number UPBTL2019B01). 


\section{RESULTS AND DISCUSSION}

\section{Morphology description}

The pileus of expanded fruit bodies sulphur yellow color in its surface, $4.5 \mathrm{~cm}$ diameter, hemispherical to parabolic, with loosely scattered minute, floccose squamules, the margin sulcate (Figure 1). Stipe $7.5 \mathrm{~cm} \times 0.8 \mathrm{~cm}$, cylindrical, hollow, with a prominent swollen base and pad of mycelium at the base (Figure 1). Volva absent. Annulus, attached to the upper third of the stipe, membranous, sulphur yellow color as the stipe (Figure 1) and appears quickly fading. Basidiospores hyaline, thick-walled, ellipsoid, slightly truncated at the apex by small but distinct germ pore (Figure 1), dimensions $5.1(4.1$ - 6.2) x 3.5 (3.2 - 4.0) $\mu \mathrm{m}$, the spore print white color (Figure 1). Clamp connections were not found. Leucocoprinus birnbaumii is growing alone or in clusters in flower pots year-round and lawns etc. in warm conditions (Dutta et al. 2011). The fungus breaks down dead organic matter in the potting soil.

\section{Identification and taxonomy}

Features characteristic to $L$. birnbaumii are the hemispherical to parabolic, sulphur yellow color, sulcate striate pileus, covered by floccose squamules of the same color, free lamellae and elongated, yellow stipe with bulbous base (Dutta et al. 2011). Leucocoprinus cepistipes (Sowerby) Pat., another closer species, recorded in Sri Lanka (Pegler, 1986) is different from L. birnbaumii in its white color pileus with pale brown disc, white to cream color lamellae and the same color stipe. Annulus is membranous, yellowish as the stipe and attached to upper third of the stipe.

The fungus belongs to the Kingdom Fungi, Phylum Basidiomycota, Order Agaricales, Family Agaricaceae, Genus Leucocoprinus and Leucocoprinus birnbaumii
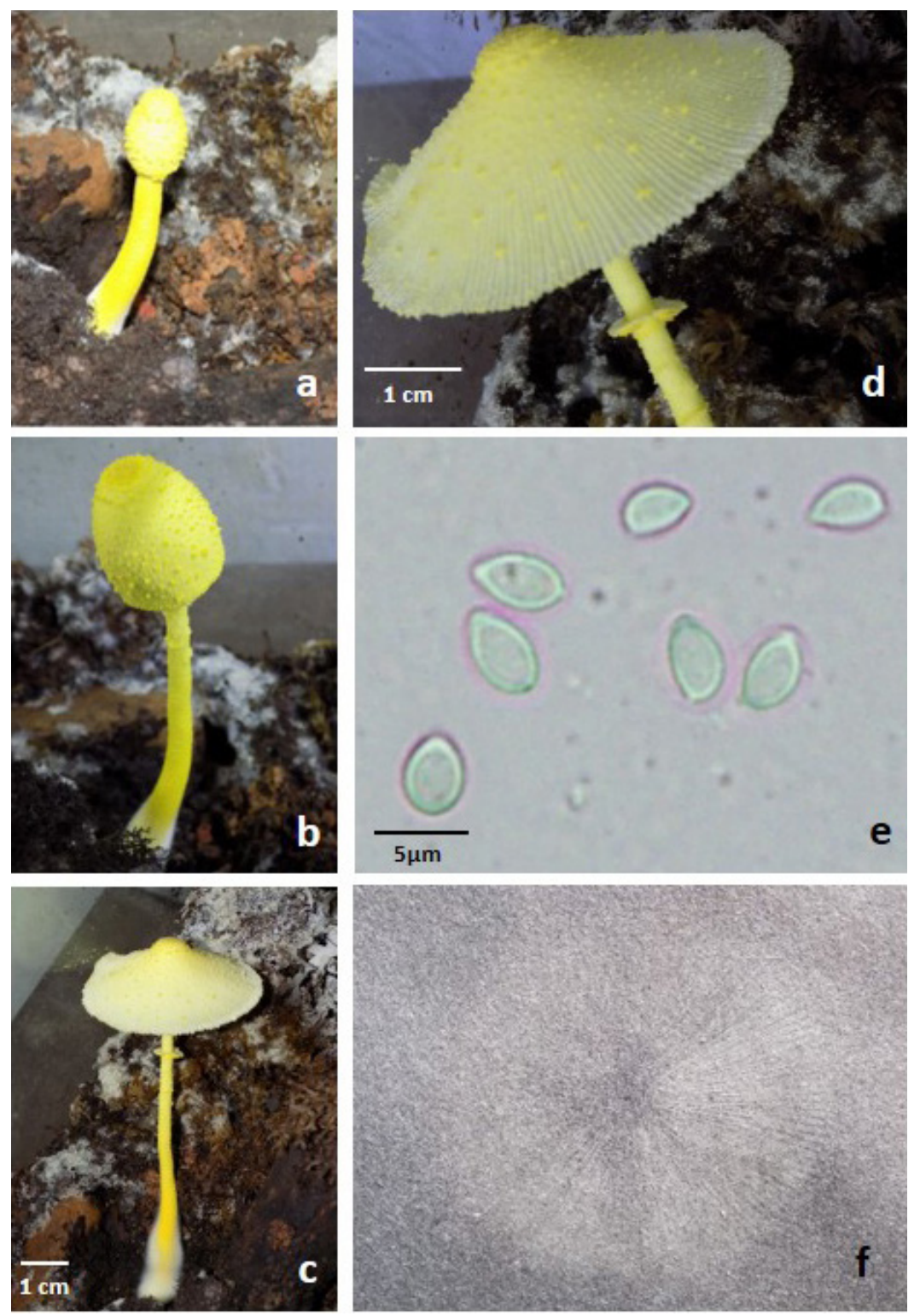

Figure 1: Fruit bodies of Leucocoprinus birnbaumii that appeared on decaying mosses indoors at different stages of development, $\mathrm{a}$ - b-younger and c - mature stages of the expanded mushroom, d sulphur yellow, convex, pileus with loosely-scattered minute, floccose squamules and sulcate margin; the membranous annulus attached to the upper third of the stipe, the color is same as the stipe, e- basidiospores, and f- white color spore print. 
(Corda) Singer.

Synonyms of L. birnbaumii include Agaricus luteus Bolton (Bolton, 1788), A. birnbaumii Corda (Corda, 1839), A. flos-sulphuris Schnizl. (Sturm, 1851), Bolbitius birnbaumii (Corda) Sacc. \& Traverso (Saccardo and Traverso, 1910), Lepiota aurea Massee (Messee, 1912), L. lutea, L. copronoides, L. pseudolicmophora Rea. (Rea, 1922), Leucocoprinus luteus, (Locquin, 1945) and L. flossulphuris (Schnizlein) Cejp.

Petch (1910) referred this fungus to be common and often found in the Peradeniya area with large numbers of young, stages springing up close to the bases of expanded mushrooms. However, there had been no records of the species over a period of more than a century in the country. This may indicates the overall scarcity of taxonomical studies on macrofungi over the past decades in Sri Lanka.

\section{ACKNOWLEDGEMENTS}

Authors gratefully acknowledge Nilanka de Silva for digital microscopic imaging.

\section{DECLARATION OF CONFLICT OF INTEREST}

Authors declare no conflict of interest.

\section{REFERENCES}

Berkeley, M.J. (1847). Decades of fungi. Decade XV-XIX Ceylon fungi. London Journal of Botany 6: 479-514.

Berkeley, M.J. and Broome, C.E. (1871). The fungi of Ceylon. (Hymenomycetes, from Agaricus to Cantharellus). Botanical Journal of the Linnean Society 11(56): 494-567.
Bolton, J. (1788). A History of Fungusses, Growing about Halifax 2:45-92.

Corda, A.C.J. (1839). Icones fungorum hucusque cognitorum 3: 1-55.

Dutta, A.K., Pradhan, P., Giri, S., Roy, A. and Acharya, K. (2011). Leucocoprinus birnbaumii (Corda) Singer: An addition to macrofungal flora of West Bengal, India. Journal of Mycology and Plant Pathology 41(2): 316318.

Massee, G.E. (1912). Fungi exotici, XIII. Bulletin of Miscellaneous Information of the Royal Botanical Gardens Kew, 189-191.

Locquin, M. (1945). Notes sur les Lepiotes. II. Bulletin Mensuel de la Société Linnéenne de Lyon. 14(5): 89100.

Pegler, D.N. (1986). Agaric flora in Sri Lanka. Kew Bulletin Additional Series XII. Kew, London: Royal Botanical Gardens. HMSO Publication Centre, London 519pp.

Petch, T. (1910). Revisions of Ceylon fungi (Part II). Annals of the Royal Botanic Gardens Peradeniya 4: 73-444.

Rea, C. (1922). British Basidiomycetae: A handbook to the larger British fungi $1-799$.

Saccardo, P.A. and Traverso, J.B. (1910). Index Iconum Fungorum, Vol. I. Sylloge Fungorum 19:-1158.

Senthilarasu, G. (2014). Diversity of agarics (gilled mushrooms) of Maharashtra, India. Current Research in Environmental \& Applied Mycology 4(1): 58-78.

Singer, R. (1962). Diagnoses fungorum novorum Agaricalium II. Sydowia 15(1-6): 45-83.

Sturm, J. (1851). Deutschland. Flora 3(32):2. 